\title{
EL ESTATUTO DE RESPONSABILIDAD GIVIL EN LOS CONVENIOS DE GINEBRA Y SU APLICACIÓN POR LOS TRIBUNALES DE JUSTICIA CHILENOS*
}

\author{
THE CIVIL LIABILITY STATUTE IN THE GENEVA CONVENTIONS \\ AND ITS APPLICATION BY THE CHILEAN \\ COURTS OF JUSTICE
}

\section{Regina Ingrid DíAz TOLOSA**}

RESUMEN: Este artículo examina la discusión sobre la prescripción de las acciones civiles reparatorias en casos de crímenes de lesa humanidad, y en especial la interpretación de los jueces chilenos al aplicar los Convenios de Ginebra de 1949. Conforme a cánones de interpretación del derecho internacional, se considera como principio básico la reparación integral de las víctimas (o sus familiares) de violaciones a la dignidad humana; por tanto, la imprescriptibilidad de estos crímenes es aplicable no sólo tratándose de responsabilidad penal, sino también de la civil.

Palabras clave: crímenes de lesa humanidad, imprescriptibilidad, responsabilidad civil, derecho internacional humanitario, cánones de interpretación
ABSTRACT: This article examines the discussion on the prescription of civil remedial actions in cases of crimes against humanity, and especially, Chilean judges' interpretation on this statute, applying the 1949 Geneva Conventions. According to the canons of interpretation of International Lare, it is considered as basic principle the reparation of the victims (or their families) of violations of human dignity, therefore the imprescriptibly of these crimes are applicable not only to criminal liability, also to civil.

Keywords: war crimes and against humanity, prescription, civil liability, international humanitarian law, interpretation canons.

* Artículo recibido el 28 de noviembre de 2018 y aceptado para su publicación el 30 de septiembre de 2019.

** ORCID: 0000-0001-5447-0049. Doctora en Derecho. Integra el claustro académico del Doctorado en Derecho de la Universidad Autónoma de Chile, Santiago, en la línea de investigación sobre "Justicia Constitucional y Derechos Humanos". Se desempeña en gestión como directora de Carrera de Derecho, sede Santiago, Universidad Autónoma de Chile, Santiago. Correo electrónico:ingrid.diaz@uautonoma.cl.

Boletín Mexicano de Derecho Comparado, nueva serie, año LI, núm. 156, septiembre-diciembre de 2019, pp. 1361-1382.

Esta obra está bajo una Licencia Creative Commons Atribución-NoComercial-SinDerivar 4.0 Internacional, IIJ-UNAM. 
SUMARIO: I. Introducción. II. La prescriptibilidad de las acciones civiles reparatorias en casos de violaciones graves al DIH. Tendencia jurisprudencial prevalente en Chile entre 2006-2014. III. La imprescriptibilidad integral de las acciones que persiguen la sanción de los crímenes de lesa humanidad. Tendencia jurisprudencial mayoritaria en Chile a partir de 2015. IV. El estatuto de responsabilidad civil de los Convenios de Ginebra. V. Conclusiones. VI. Referencias bibliográficas.

\section{INTRODUCGIÓN}

Los Convenios de Ginebra de 1949 son los instrumentos internacionales principales que codifican las normas del derecho internacional humanitario, aquellas normas internacionales que regulan las formas en que se pueden librar los conflictos armados, y que intentan limitar los efectos de éstos, protegiendo especialmente a las personas que no participan en las hostilidades (civiles, personal sanitario, miembros de organizaciones humanitarias) y a los que ya no pueden seguir participando en éstas (heridos, enfermos, náufragos, prisioneros de guerra) (Comité Internacional de la Cruz Roja 2014).

Chile ratificó estos Convenios el 12 de octubre de 1950 (Comité Internacional de la Gruz Roja 2014) y les otorgó vigencia interna a través del Decreto Supremo 752 publicado en el Diario Oficial el 17 de abril de 1951. Sus tribunales superiores de justicia los han aplicado e interpretado a propósito de casos relacionados con vulneraciones a los derechos humanos acaecidos durante el gobierno de Augusto Pinochet Ugarte, especialmente en los periodos en que rigió la declaración de estado de sitio por conmoción interior, pues si bien no existía una declaración formal y expresa de guerra civil, se interpretaba al estado de sitio como estado de guerra para efectos de la aplicación de los tribunales militares de tiempos de guerra. En efecto, el artículo 1o. del Decreto Ley 5, 1973, indica:

Declárese, interpretando el artículo 418 del Código de Justicia Militar que el Estado de Sitio decretado por conmoción interna, en las circunstancias que vive el país, debe entenderse "estado o tiempo de guerra" para los efectos de la penalidad de ese tiempo que establece el Código de Justicia Militar y demás leyes penales y, en general, para todos los demás efectos de dicha legislación. 
Luego, el estado de sitio por conmoción interna estuvo vigente entre el 11 de septiembre de 1973 y el 10 de marzo de 1978, y entre el 6 de noviembre de 1984 y el 17 de junio de 1985. En complemento, el artículo 418 del Código de Justicia Militar estableció que "se entiende que hay estado de guerra o que es tiempo de guerra, no solo cuando ha sido declarada oficialmente la guerra o el estado de sitio, en conformidad a las leyes respectivas, sino también cuando de hecho existiere la guerra o se hubiere decretado la movilización para la misma, aunque no se haya hecho la declaración oficial".

La jurisprudencia de los tribunales chilenos superiores de justicia ha discutido la aplicabilidad interna de estos Convenios. En una primera etapa (1990-8), los sentenciadores negaban su aplicación por no darse el supuesto para ello, a saber: la existencia de un conflicto bélico efectivo. Luego (1998-2005) aceptan aplicarlos para fundar la imprescriptibilidad de los crímenes de lesa humanidad, al interpretar que la declaración de estado de sitio como estado de guerra realiza una ficción legal de guerra, que hace aplicable el uso de tal normativa internacional (Díaz 2006). Así, se reconoce que la imprescriptibilidad de estos crímenes es un principio perteneciente al derecho internacional consuetudinario, que encuentra su consagración convencional en el artículo 3o. común de los Convenios de Ginebra de 1949, que señala que estos crímenes quedan prohibidos "en cualquier tiempo y lugar". De esta forma, la prescripción, tanto en lo que se refiere a la persecución del delito como a la imposición de la sanción que en su caso corresponda, nunca puede oponerse como causal de exención de la responsabilidad penal (Bustos 2000; Horvitz 2006).

A partir de 2006, la discusión se ha trasladado a las consecuencias o efectos de la aplicación de estos Convenios en el ámbito de la responsabilidad civil (Aguilar 2009; Feddersen 2010). Al respecto, existen dos posturas jurisprudenciales contrapuestas en materia de prescripción de las acciones civiles que persiguen reparar a las víctimas (o sus familiares) de crímenes internacionales repudiados por los Convenios de Ginebra. En el periodo 2006-2014 prevaleció la postura de la prescripción de las acciones civiles reparatorias en casos de violaciones graves al derecho internacional humanitario (en adelante DIH) (sección II); luego, a partir de 2015, la tendencia jurisprudencial mayoritaria reconoce la imprescriptibilidad integral de las acciones que persiguen la sanción de los crímenes de lesa humanidad (sección III). Ante esta dicotomía, se hace necesario enfatizar 
que en el ámbito de las relaciones entre el derecho internacional y los derechos internos, la aplicación interna de las normas internacionales se ha de realizar con una interpretación de sus disposiciones conforme a los parámetros de interpretación propios del derecho internacional. Por tanto, en el ámbito específico del DIH, la aplicación interna que realicen los tribunales de justicia domésticos han de interpretar tales normas conforme a criterios teleológicos y sistemáticos, y no desde una perspectiva local, aplicando criterios propios del sistema jurídico doméstico, desconociendo el plexo normativo internacional. En específico, los jueces que apliquen el estatuto de responsabilidad establecido en los Convenios de Ginebra, para concluir si procede o no la prescripción de las acciones civiles que emanan de las infracciones graves del DIH, ineludiblemente han de analizar las fuentes del derecho internacional, que permiten una mejor comprensión del sentido y alcance de tales disposiciones (sección IV).

\section{LA PRESCRIPTIBILIDAD DE LAS ACGIONES GIVILES REPARATORIAS EN GASOS DE VIOLACIONES GRAVES AL DIH. TENDENCIA JURISPRUDENCIAL PREVALENTE EN CHILE ENTRE 2006-2014}

A favor de la prescripción de estas acciones civiles, se arguyen razones de paz social y de certeza jurídica, pues se afirma que estas "constituye[n] un principio general del derecho" que "adquiere[n] presencia en todo el espectro de los distintos ordenamientos jurídicos, salvo que, por ley o en atención a la naturaleza de la materia, se determine lo contrario, esto es, la imprescriptibilidad de las acciones" (Ávila c. Fisco de Chile 2009, pár. 9; Castillo y otros c. Fisco de Chile 2014, pár. 7; Contra Estado de Chile 2011, pár. 11; Felber y otros c. Fisco de Chile 2015, pár. 7; Martínez y otros c. Fisco de Chile 2006, pár. 13; Rivas y otros c. Fisco de Chile 2010, pár. 9; Salgado c. Fisco de Chile 2014, pár. 7; Vásquez c. Fisco de Chile 2014, pár. 9; Zúñiga y otros c. Contreras y otros 2017, pár. 4).

Luego, no se considera que la imprescriptibilidad de la acción penal arrastre la imprescriptibilidad de las acciones reparatorias que surgen de la comisión del ilícito, y, por consiguiente, se aplica el plazo de cuatro años desde la perpetración del acto para establecer la prescripción de las acciones, conforme a la regla del artículo 2332 del Código Civil chileno sobre responsabilidad extracontractual, pues se considera que "tratándose 
de acciones de contenido patrimonial no es posible desentenderse de las normas generales que gobiernan la materia corresponde también aplicar las reglas del derecho común contenidas en el Código Civil en materia de prescripción extintiva, máxime cuando existe norma expresa que señala que las reglas relativas a ella se aplican igualmente a favor y en contra del Estado" (Abarzúa y otros c. Fisco de Chile 2013, párs. 1-4; Ávila c. Fisco de Chile 2009, párs. 7, 11 y 12; Castillo y otros c. Fisco de Chile 2014, pár. 3, 8 y 9; Contra Estado de Chile 2011, párs. 7, 12 y 13; Felber y otros c. Fisco de Chile 2015, párs. 5 y 8; Martínez y otros c. Fisco de Chile 2006, párs. 14-7; Ortega c. Fisco de Chile 2008, pár. 1; Rivas y otros c. Fisco de Chile 2010, párs. 5, 10-2; Salgado c. Fisco de Chile 2014, párs. 4, 8 y 9; Vásquez c. Fisco de Chile 2014, párs. 5, 10 y 11; Zúñiga y otros C. Contreras y otros 2017, pár. 1). En Argentina, la jurisprudencia ha tenido una evolución similar, en tanto las demandas judiciales de reparación civil por crímenes ejecutados por agentes estatales en el marco del gobierno militar (1976-1983) generaron posturas antagónicas sobre la prescripción de la acción civil por crímenes de lesa humanidad. Así, la Corte Suprema de Justicia de la Nación diferencia entre imprescriptibilidad de acciones penales y civiles, y rechaza la posibilidad de aplicación de la imprescriptibilidad respecto de las últimas y declarando su prescripción en virtud del artículo 3980 del Código Civil de la Nación Argentina: "el derecho de reclamar los daños y perjuicios es materia disponible y renunciable, mientras que la persecución de los delitos de lesa humanidad, se funda en la necesidad de que los crímenes de esa naturaleza no queden impunes; es decir, en razones que exceden el interés patrimonial de los particulares afectados" (Martínez D. 2017; Olivares c. Estado Nacional Argentino 1988; Larrabeiti y otro c. Estado Nacional 2007; Sommer 2018).

Para considerar estas acciones civiles imprescriptibles, los tribunales chilenos exigen la existencia de una norma expresa que declare la improcedencia de la prescripción, y específicamente, se afirma la existencia de un vacío en los Convenios de Ginebra y sus protocolos adicionales respecto a la prescripción de las acciones civiles reparatorias, por lo que no cabría presumir que el derecho internacional se opone a reconocer efectos jurídicos al transcurso del tiempo: "[E]n ausencia de [estas reglas], corresponde estarse a las del derecho común, referidas específicamente a la materia la Convención de Ginebra sobre Tratamiento de los Prisioneros de Guerra debe entenderse necesariamente referida a infracciones del orden 
penal" (Ávila c. Fisco de Chile 2009, pár. 9; Castillo y otros c. Fisco de Chile 2014, párs. 4-6; Contra Estado de Chile 2011, pár. 8; Felber y otros c. Fisco de Chile 2015, pár. 6; Martínez y otros c. Fisco de Chile 2006, pár. 20; Ortega c. Fisco de Chile 2008, pár. 2; Rivas y otros c. Fisco de Chile 2010, párs. 6 y 7; Salgado c. Fisco de Chile 2014, párs. 5 y 6).

Por otra parte, se estima que otros instrumentos internacionales, aunque se refirieran a la imprescriptibilidad de las acciones por vulneraciones a la dignidad humana, tales como la Convención Americana sobre Derechos Humanos, no serían aplicables si no se encontraban vigentes en el momento de la comisión de los delitos (Abarzúa y otros c. Fisco de Chile 2013, pár. 4; Ávila c. Fisco de Chile 2009, pár. 9; Martínez y otros c. Fisco de Chile 2006, párs. 18 y 19; Vásquez c. Fisco de Chile 2014, párs. 6 y 8; Zúñiga y otros c. Contreras y otros 2017, pár. 2).

También la Corte Suprema chilena ha estimado que el Estado ya ha dado cumplimiento al resarcimiento a través de beneficios otorgados a través de las leyes 19.123 y 19.980, y que no se puede demandar indemnización por los mismos hechos que dieron lugar a los beneficios (Galdámez 2011). ${ }^{1}$

Por otra parte, en ciertas ocasiones los tribunales no dan lugar a la demanda civil en contra del fisco de Chile por crímenes de lesa humanidad que hayan impetrado funcionarios públicos, pues estiman que los tribunales penales son incompetentes para conocer de las indemnizaciones de perjuicios solicitadas porque sólo, excepcionalmente, en sede penal se puede demandar civilmente, pero exclusivamente con relación a los mismos hechos y procesados por la comisión de los delitos investigados, no extendiéndose al tercero civilmente responsable, que en este caso sería el Estado (Lejderman c. Polanco y otros 2009, párs. 38-43; Toro y otros c.

1 La Ley 19.123, publicada en el Diario Oficial el 8 de febrero de 1992 y actualizada el 10 de diciembre de 2009, crea la Corporación Nacional de Reparación y Reconciliación y establece pensión de reparación y otros beneficios en favor de los familiares de las víctimas de violaciones a los derechos humanos o de la violencia política, que se individualizan en el volumen segundo del Informe de la Comisión Nacional de Verdad y Reconciliación y de las que se reconozcan en tal calidad por la Corporación Nacional de Reparación y Reconciliación, de conformidad con el procedimiento establecido en la misma ley. Biblioteca del Congreso Nacional, disponible en: http://bcn.cl/1vuwr (visitada 26 de enero de 2018).

La Ley 19.980 publicada en el Diario Oficial el 9 de noviembre de 2004 y actualizada el 10 de diciembre de 2009, modifica a la Ley 19.123, ampliando beneficios. Biblioteca del Congreso Nacional, disponible en: http://bcn.cl/1uypo (visitada 29 de septiembre de 2019).

Esta obra está bajo una Licencia Creative Commons

Atribución-NoComercial-SinDerivar 4.0 Internacional, IIJ-UNAM.

Boletín Mexicano de Derecho Comparado, núm. 156, pp. 1361-1382. 
Contreras y otros 2007, párs. 20-3). Sin embargo, cabe tener presente que sobre la procedencia y alcances del ejercicio de la acción civil en juicio penal tampoco existe uniformidad de interpretación, pues la Corte Suprema chilena también ha sostenido que

...la pretensión indemnizatoria que se admite en sede penal conforme a lo dispuesto en el artículo 10 del Código de Procedimiento Penal presenta como única limitación que el fundamento de la acción civil obligue a juzgar las mismas conductas que constituyen el hecho punible objeto del proceso penal, lo que viene a significar una exigencia en el campo de la causalidad (Contra Guerra y otros 2008, párs. 34-37; Toro y otros c. Contreras y otros 2009, párs. 36-40).

\section{LA IMPRESCRIPTIBILIDAD INTEGRAL DE LAS ACGIONES QUE PERSIGUEN LA SANCIÓN DE LOS GRÍMENES DE LESA HUMANIDAD. TENDENCIA JURISPRUDENCIAL MAYORITARIA EN CHILE A PARTIR DE 2015}

Esta tendencia jurisprudencial fue minoritaria en el periodo previo al 2015; no obstante, en los primeros fallos que la recogen, el núcleo central del argumento descansa en la convicción de que la imprescriptibilidad de los crímenes de lesa humanidad rige tanto para el ámbito civil como para el ámbito penal, pues la acción indemnizatoria no puede ser determinada a partir de las normas del derecho privado. Si bien las acciones se refieren a cuestiones patrimoniales, atienden a finalidades diferentes, pues las normas internacionales sobre derechos humanos reconocen, respetan y promueven la dignidad del hombre, debiéndose compensar adecuadamente a las víctimas y sobrevivientes de violaciones graves a los derechos humanos (Carrasco c. Fisco de Chile 2007, pár. 1; Contesse y otros c. Orozco y otros 2017, pár. 42; Fuenzalida y otros c. Fisco de Chile 2008, pár. 2; Montiel c. Fisco 2007, pár. 1; Muller y otro c. Fisco 2007, pár. 6; Valencia c. Fisco de Chile 2007, pár. 4; Rivas y otros c. Fisco de Chile 2010, párs. 1 y 2). En Argentina, en lo que respecta a sentencias que aceptaron la imprescriptibilidad de las acciones reparatorias, la Sala II de la Cámara Federal de Apelaciones de La Plata, en el caso Villamil (2006), falló en el sentido de ponderar la acción indemnizatoria promovida, por considerar inescindibles las acciones penales de las civiles por delitos de lesa humanidad, funda- 
mentos del alcance constitucional e internacional del derecho de reclamar sin limitación de tiempo; aunque posteriormente, sobre este caso, la Corte Suprema de Justicia de la Nación Argentina revocaría (por voto dividido) la sentencia de la Cámara Nacional. Los votos de minoría argumentaron que la acción de reparación integral (daños y perjuicios ajenos a las reparaciones pecuniarias por el solo hecho de haber estado detenido, exiliado o un familiar desaparecido) como la acción penal derivan de una misma situación de hecho, el crimen internacional (Martínez D. 2017; Villamil v. Estado Nacional 2006 [2017]; Sommer 2018).

Más adelante, los fallos chilenos que siguen esta línea afirman la existencia de un verdadero estatuto internacional de imprescriptibilidad integral, válido no sólo en lo penal, sino también en el ámbito civil, respecto de las indemnizaciones debidas en razón de la comisión de crímenes de lesa humanidad, pues

...la reparación del daño ocasionado por la infracción de una obligación internacional requiere, siempre que sea posible, la plena restitución (restitutio in integrum), la cual consiste en el restablecimiento de la situación anterior carece de sentido, frente a [una norma de] ius cogens, sostener la imprescriptibilidad para el ámbito [penal] y desestimarla para el [civil], aduciendo para ello que éste es patrimonial, así como también el derecho a la indemnización reclamada, y por lo mismo privada y renunciable (Araneda y otros c. Moren y otros 2017, pár. 11; Boettiger y otros c. Contreras y otros 2015, párs. 24 y 25; Chacaltana y otros c. Fisco de Chile y otros 2016, pár. 14; Contra Guerra y otros 2008, párs. 42 y 48; Muller y otro c. Fisco 2007, pár. 27; Pereira y otros c. Luzoro y otro 2017, pár. 21; Toro y otros c. Contreras y otros 2009, pár. 40; Valencia c. Fisco de Chile 2007, pár. 3).

Luego, la Corte enfatiza que la fuente de este estatuto de responsabilidad internacional integral es el derecho consuetudinario, y en especial los principios básicos del derecho internacional de los derechos humanos y del DIH, que gozan de carácter de ius cogens, normas imperativas de derecho internacional general que derivan su vinculatoriedad no del consentimiento de los Estados, sino de su carácter consuetudinario. Por tanto, la fuente de la responsabilidad civil está en normas y principios de derecho internacional de derechos humanos, y ello ha de ser necesariamente así porque este fenómeno de transgresiones tan graves es muy posterior al proceso de codificación que no lo considera, por responder a criterios

Esta obra está bajo una Licencia Creative Commons

Atribución-NoComercial-SinDerivar 4.0 Internacional, IIJ-UNAM.

Boletín Mexicano de Derecho Comparado, núm. 156, pp. 1361-1382. 
claramente ligados al interés privado, y por haber sido la cuestión de los derechos fundamentales normada y conceptualizada sólo en la segunda mitad del siglo XX (Carrasco c. Fisco de Chile 2007, pár. 1; Contra Flores y otro (caso Molco) 2006, pár. 5; Contra Gómez 2006, pár. 18; Contra Guerra y otros 2008, párs. 9, 10 y 13; Contra Pinto (caso Chena) 2007, pár. 14; Montiel c. Fisco 2007, pár. 2; Lejderman c. Polanco y otros 2007, pár. 11; Fuenzalida y otros c. Fisco de Chile 2008, párs. 1 y 5; Muller y otro c. Fisco 2007, párs. 7 y 25; Quiñones c. Fisco de Chile 2010, pár. 14; Toro y otros c. Contreras y otros 2009, pár. 42; Valencia c. Fisco de Chile 2007, pár. 2; Vergara c. Fisco de Chile 2009, pár. 11).

En efecto, el concepto de reparación que interesa en estos casos es el incorporado a partir de la segunda mitad del siglo XX, a través de normas de carácter supraestatal del derecho internacional de los derechos humanos. Allí se ha reconocido la reparación integral como un derecho de las víctimas de violaciones de derechos humanos, y a su vez una obligación del Estado cuando ha incumplido su deber de garantía y protección de tales derechos. Recordemos que antes de las guerras mundiales, el concepto jurídico de reparación fue construido desde el punto de vista de las relaciones entre particulares, a partir del reconocimiento de la responsabilidad civil extracontractual como una de las fuentes de las obligaciones y la máxima "el que causa un daño debe repararlo"; es decir, como un deber general de reparar los daños que se causen a otras personas, por acción o por omisión, cuando no existe un deber jurídico de soportar tales daños. Posteriormente, la teoría de la responsabilidad extracontractual fue ampliada al contexto de las relaciones entre el Estado y los particulares, en lo que se conoce como la doctrina de la responsabilidad patrimonial del Estado, que hoy en día goza de una elaboración conceptual amplia, tanto en la jurisprudencia como en la doctrina. Este enfoque tradicional concibe la reparación básicamente desde un punto de vista económico, que incluye daño emergente, lucro cesante, y daño moral, pero no sólo se valora exclusivamente en términos económicos para efectos de la reparación, sino que además es prescriptible (Martínez C. 2018; Sommer 2018). Así, fallos chilenos recientes rechazan la posibilidad de exoneración de responsabilidad civil por aplicación del derecho interno, y enfatizan que el derecho internacional (Convenios de Ginebra 1949 y Convención Americana sobre Derechos Humanos 1969) ha recogido el criterio de que "todo daño ha de ser reparado" (Lobos y otros con Fisco de Chile 2018, párs. 15 y 16). 
También, la Corte Suprema chilena refiere como argumento complementario a la jurisprudencia de la Corte Interamericana de Justicia, que ha reconocido y desarrollado este principio básico de reparar en caso de graves violaciones a la dignidad de la persona humana, a partir del artículo 63 de la Convención Americana sobre Derechos Humanos, obligación que no se anula ni aun en caso de conflictos armados:

...cuando ha habido una violación a los derechos humanos surge para el Estado infractor la obligación de reparar con el pago de una justa indemnización a la parte lesionada. De esta manera, al producirse un hecho ilícito imputable a un Estado surge de inmediato la responsabilidad internacional de éste por la violación de una norma internacional, con el consecuente deber de reparación y de hacer cesar las consecuencias de la violación (Contra Barría 2007, pár. 19; Contra Gómez 2006, párs. 13 y 18; Lejderman c. Polanco y otros 2007, pár. 11; Montiel c. Fisco 2007, pár. 3; Muller y otro c. Fisco 2007, párs. 8-12, 24 y 25; Fuenzalida y otros c. Fisco de Chile 2008, pár. 1; Pereira y otros c. Luzoro y otro 2017, pár. 22; Valencia c. Fisco de Chile 2007, pár. 6).

Por otra parte, la Corte Suprema agrega que otorgarles un tratamiento desigual en materia de prescripción a las acciones penal y civil que emanan de la comisión de un crimen de lesa humanidad es discriminatorio y no permite al ordenamiento jurídico guardar la coherencia y unidad que se le reclama. Entonces, pretender aplicar las normas del Código Civil a la responsabilidad derivada de este tipo de crímenes resulta improcedente, por cuanto la evolución de las ciencias jurídicas ha permitido establecer principios y normas propios para determinadas materias, lo cual el mismo Código reconoce, al estipular en el artículo 4o. que las disposiciones especiales se aplicarán con preferencia a las de este Código, lo que es pertinente a las nuevas realidades y situaciones emergentes, como sucede en este caso, al tratarse de una materia con postulados diversos y a veces en pugna con los del derecho privado regulador de las relaciones en un plano de igualdad y de autonomía de las personas para obligarse, pues es una rama representativa de la supremacía de su finalidad centrada en la dignidad de la persona a quien se debe servir, por lo que se aparta de los postulados que son propios del derecho privado (Araneda y otros c. Moren y otros 2017, pár. 9; Arévalo y otros c. Rubilar y otros 2015, pár. 12; Arratia y otros c. Corbalán y otro 2016, pár. 16; Atencio y otros c. Espinoza y otros 
2016, pár. 17; Contra González y otros 2016, pár. 21; Corvalán y otros c. Espinoza y otros 2016, pár. 17; Drouilly y otros c. Krassnoff y otros 2016, pár. 23-25; Eltit y otro c. González y otros 2016, pár. 15; Figueroa c. Fisco de Chile 2016, pár. 5; Flores y otros c. Olguín y otros 2016, pár. 7; Gómez y otros c. Fisco de Chile 2016, párs. 15-17; Lastra c. Fisco de Chile 2017, pár. 5; Marcone c. Fisco de Chile 2015, párs. 5-7; Núñez c. Estay y otros 2016, pár. 20; Pinochet c. Salas y otros 2017, pár. 70; Sepúlveda c. Fisco de Chile 2016, párs. 5-7).

Luego, respecto de los beneficios otorgados a través de las leyes 19.123 y 19.980, la Corte también ha indicado que éstos no son impedimento para reparar materialmente el daño moral sufrido como consecuencia de la comisión de un crimen de lesa humanidad cuya certeza se obtiene recién con el proceso. La "pensión de reparación es compatible con otras indemnizaciones que judicialmente pudiere impetrarse y obtenerse por los beneficiarios" (Boettiger y otros c. Contreras y otros 2015, pár. 22; Brevis c. Fisco de Chile 2017, pár. 9; Chacaltana y otros c. Fisco de Chile y otros 2016, pár. 15; Contra Guerra y otros 2008, párs. 49 y 50; Garcés y otros c. Espinoza y otros 2017, pár. 9; González c. Arellano 2008, pár. 14; Lastra c. Fisco de Chile 2017, pár. 5; Montecinos c. Fisco de Chile 2015, pár. 3; Pereira y otros c. Luzoro y otro 2017, pár. 15; Quiñones c. Fisco de Chile 2010, pár. 20; Toro y otros c. Contreras y otros 2009, pár. 45; Vergara c. Fisco de Chile 2009, pár. 15; Villalobos c. Moren y otro 2016, pár. 22).

En cuanto a si es posible extender la responsabilidad civil al Estado en el caso de la comisión de estos crímenes, la Corte indica que aquel no puede eludir su responsabilidad de reparación, pues se trata de delitos cometidos por militares en el ejercicio de su función pública, en que durante un periodo de extrema anormalidad institucional representaban al gobierno de la época, y en que se abusó de aquella potestad y representación, produciendo ofensas de gravedad. La reparación integral del daño no sólo se limita a los autores de los crímenes, sino también al mismo Estado (Aguilera y otros c. Manríquez y otro 2016, pár. 14; Álvarez y otros c. Moren y otros 2015, pár. 24; Caballero y otros c. Salazar 2017, pár. 31 ; Maturana y otros c. Manzo y otros 2016, pár. 14; Meza y otro c. Contreras y otros 2015, párs. 5 y 6; Moreno y otro c. Manríquez y otros 2017, pár. 17; Pinto c. Fisco de Chile 2016, pár. 4; Sardy c. Fisco de Chile 2016, párs. 5-7; Sepúlveda y otro c. Consejo de Defensa del Estado 2018, pár. 5; 
Tapia y otros c. Moren y otros 2017, pár. 40; Valencia y otros c. Fisco de Chile 2015, párs. 3-5).

\section{El ESTATUTO DE RESPONSABILIDAD CIVIL DE LOS CONVENIOS DE GINEBRA}

El texto de los Convenios de Ginebra no refiere expresamente a la imprescriptibilidad de las acciones civiles reparatorias en caso de graves transgresiones al DIH, sino que sólo indican que "[n]inguna Parte Contratante podrá exonerarse, ni exonerar a otra Parte Contratante, de las responsabilidades en que haya incurrido" (artículo común a los cuatro Convenios de Ginebra 1949: artículo 51 del I Convenio, artículo 52 del II, artículo 131 del III y artículo 148 del IV). Luego, cabe preguntarse si es posible desde esta disposición colegir un estatuto de reparación integral tratándose de la comisión de crímenes de lesa humanidad.

Para encontrar una respuesta, se debe recordar que la regla general de interpretación de los tratados internacionales, recogida en el artículo 31 de la Convención de Viena sobre el Derecho de los Tratados, reconoce como métodos de interpretación fundamentales uno objetivo, que se basa en el texto mismo del tratado, y el teleológico, que aspira a llegar al resultado interpretativo más acorde con el objeto y fin del tratado (Pagliari 2007; Shaw 2008). Luego, sólo si no es esclarecedor se puede acudir de manera complementaria a un método subjetivo, recogido en el artículo 32 de la citada Convención, que busca conocer la intención de las partes, al examinar los trabajos preparatorios de codificación (Gutiérrez y Cervell 2008; Jiménez et al. 2005; Pagliari 2007; Shaw 2008).

Así, se considera que la manifestación auténtica de las partes debe buscarse como punto de referencia inexcusable en el texto del tratado, y no fuera de él. Y que los términos utilizados en el texto se han de entender en su sentido ordinario, salvo que se desprenda de él un sentido particular. Además, se ha de considerar su contexto, entendiéndose por tal el preámbulo y sus anexos, y todo acuerdo concertado con motivo de su celebración, incluidas resoluciones adoptadas para patrocinar el texto del tratado o las aclaraciones o interpretaciones del presidente del comité de redacción de la conferencia de plenipotenciarios en la que se adoptó el tratado (Gutiérrez y Cervell 2008; Jiménez et al. 2005; Pagliari 2007; Shaw 2008). 
También, los acuerdos ulteriores entre las partes acerca de la interpretación del tratado o de su aplicación, toda práctica seguida en la aplicación de tratado por la que consta el acuerdo de las partes acerca de su interpretación y toda norma pertinente de derecho internacional aplicable en las relaciones entre las partes, y en vigor en el momento en que la interpretación tiene lugar, a menos que el propio tratado establezca que se ha de interpretar conforme a las normas existentes al momento de su celebración (Gutiérrez y Cervell 2008; Jiménez et al. 2005).

Por otra parte, la referencia al criterio teleológico enfatiza la necesaria consideración de los elementos pertinentes a la naturaleza del tratado. Además se ha de considerar, tal como lo ha realizado la Comisión de Derecho Internacional de las Naciones Unidas, a propósito de sus trabajos sobre la fragmentación del derecho internacional, que todo tratado debe interpretarse en el sentido de presumir que las partes al abordar sus disposiciones no han querido incumplir ni las normas consuetudinarias prexistentes ni los principios generales del derecho; asimismo las partes reenvían a esas normas y principios respecto de todas las cuestiones no resueltas por él, de manera explícita o implícita, en virtud del principio de interpretación sistemática. Con todo, el proceso interpretativo debe verificarse de buena fe procurando alcanzar una interpretación razonable y no abusiva; es decir, la interpretación que debe seguirse es aquella que permita un efecto útil acorde con el objeto y el fin del tratado (Gutiérrez y Cervell 2008; Naciones Unidas 2006; Novak 2013; Pagliari 2007).

Así, en la materia es pertinente examinar y contrastar no sólo las disposiciones de los Convenios de Ginebra, sino también otros documentos atinentes al tópico en estudio emanados de la Conferencia Internacional de la Cruz Roja u otros organismos internacionales, que nos permitan determinar el contenido de esas "responsabilidades" a las que alude el texto de los Convenios de Ginebra.

El Comité Internacional de la Cruz Roja, "guardián” del derecho internacional humanitario (Sandoz 1998), elaboró durante el decenio de los cincuenta los comentarios a los artículos de los Convenios. El comentario al artículo 51 del I Convenio de Ginebra fue actualizado en 2016, y remite en forma complementaria al comentario de 1987 al artículo 91 del Protocolo Adicional I. El comentario al I Convenio indica que la expresión "responsabilidades" ("any liability" en la versión en inglés) contenida en el artículo 51 evoca a la responsabilidad de los Estados partes 
por infracciones graves cometidas por sus fuerzas armadas o personas que hayan actuado bajo su autoridad o comando, y requiere que el Estado responsable haga una reparación total por la pérdida o lesiones causadas por infracciones graves. Este principio de reparación se encuentra incluido en varios tratados, incluyendo el artículo 3o. de la IV Convención de La Haya de 1907, relativo a las leyes y costumbres de la guerra terrestre, que expresamente alude a la obligación de la parte beligerante que viole estas disposiciones a indemnizar. Luego, el comentario al I Protocolo (artículo 91) precisa que esta indemnización se requerirá siempre que no se pueda retrotraer la situación a aquella existente antes de la violación. Esta compensación usualmente se expresa en una suma de dinero, la cual debe corresponder al valor del objeto cuya restitución no es posible, o a una indemnización proporcional a la pérdida sufrida (Comité Internacional de la Cruz Roja).

Luego, se ha entendido el término "reparaciones" de forma amplia para referirse a todas aquellas medidas que se pueden adoptar para resarcir los diversos tipos de daño que puedan haber sufrido las víctimas como consecuencia de estos crímenes. Estas medidas incluyen: a) restitución, es decir, restablecer el statu quo ante de la víctima; b) compensación de los daños sufridos a través de la cuantificación de éstos; c) rehabilitación, atención social, médica y psicológica, así como servicios legales; d) satisfacción y garantías de no repetición, categoría especialmente amplia, incluyen $v$. $g$. cese de las violaciones, verificación de hechos, disculpas oficiales y sentencias judiciales que restablecen la dignidad y la reputación de las víctimas, plena revelación pública de la verdad, búsqueda, identificación y entrega de los restos de personas fallecidas o desaparecidas junto con la aplicación de sanciones judiciales o administrativas a los autores de los crímenes (Convención Americana sobre Derechos Humanos 1969, artículo 63; Convención contra la Tortura y Otros Tratos o Penas Crueles, Inhumanos o Degradantes 1984, artículo 14; Convención Interamericana para Prevenir y Sancionar la Tortura 1985, artículo 9o.; Convención Internacional para la Protección de todas las personas contra las Desapariciones Forzadas 2006, artículo 24; De Greiff 201 1; Estatuto de la Corte Penal Internacional 1998, artículo 75; Martínez C. 2018).

En cuanto al objeto y fin de estos Convenios, es preciso tener en consideración que tienen por propósito garantizar un mínimo de humanidad en los procesos de conflictos armados, y que las conductas considera- 
das graves - establecidas en el artículo 3o. común de los Convenio- de cometerse, configuran crímenes internacionales de carácter de ius cogens (véase por ejemplo, Prosecutor v. Akayesu 1998; Prosecutor v. Rutaganda 1999; Prosecutor v. Musema 2000; Prosecutor v. Delacic et al. 2001) que generan obligaciones erga omnes, es decir, el derecho de todos y cada uno de los miembros de la comunidad internacional a demandar el cese de la violación y a hacer valer la responsabilidad emergente consecuente; reparación plena cuyo régimen jurídico de responsabilidad tiene su fundamento en la naturaleza de la obligación violada y en la gravedad de la ésta (Acosta 1995; Cebada 2002; Meron 1987; Sánchez 2014).

Por otra parte, se debe considerar que todo perjuicio causado por cualquier hecho internacionalmente ilícito exige una total e integral reparación, lo cual implica restablecer la situación existente con anterioridad a la vulneración o compensar al afectado por las consecuencias adversas de la ilicitud cometida (Calderón 2015; Gómez-Robledo 2003). A este respecto, el documento sobre Responsabilidad Internacional de los Estados por Hechos Ilícitos (Comisión de Derecho Internacional 2001), en su artículo 31, señala respecto del deber de reparación: “1. El Estado responsable está obligado a reparar íntegramente el perjuicio causado por el hecho internacionalmente ilícito. 2. El perjuicio comprende todo daño, tanto material como moral, causado por el hecho internacionalmente ilícito del Estado". Este principio ya tenía reconocimiento en la Corte Permanente de Justicia Internacional en el caso de la Fábrica de Chorzów (1928) como reparación integral a aquella que invalida los efectos del acto ilegal y restablece la situación al estado anterior de la violación. Por cierto, reconocimiento inicial de la reparación como una cuestión de responsabilidad entre Estados; un deber de los Estados por su incumplimiento a un compromiso internacional. Posteriormente, se reconoció también la reparación a individuos como un derecho de titularidad de las víctimas de violaciones a los derechos humanos. A su vez, se le ha otorgado a este derecho una doble dimensión. Por un lado, una dimensión sustantiva, que se traduce en el derecho de la víctima a ser reparada, y a su vez en la obligación del Estado de reparar el daño sufrido. Y por otro, una dimensión procesal, que se subsume en la obligación estatal de proporcionar recursos efectivos para garantizar ese resarcimiento (Calderón 2015; Martínez C. 2018). Así, destaca la Opinión Consultiva de la Corte Internacional de Justicia sobre la legalidad de la construcción de un muro israelí en terri- 
torios ocupados por palestinos (2004) en cuanto reconoce la obligación entre el Estado y los individuos, al sostener que Israel debiera pagar una compensación a las víctimas de los daños ocasionados por la destrucción de las propiedades debido al muro, por violar normas del derecho internacional humanitario y el derecho internacional de los derechos humanos (Cebada 2002; Crawford 2004; Henckaerts y Doswald-Beck 2007; Zegveld 2010).

Este principio ha sido reconocido también en el ámbito de los sistemas de protección de los derechos humanos. En efecto, la Corte Interamericana de Derechos Humanos ha desarrollado una jurisprudencia en relación con la obligación de investigar y sancionar íntegramente la comisión de crímenes internacionales que violan prohibiciones de carácter ius cogens, con base en el artículo 63 de la Convención Americana sobre Derechos Humanos, denominada restitutio in integrum, entendiendo que la reparación consiste en la plena restitución, que incluye el restablecimiento de la situación anterior, pero además, la reparación de las consecuencias que la infracción produjo, a través del pago de una indemnización como compensación por los daños patrimoniales y extrapatrimoniales, incluyendo el daño moral (por ejemplo, Aloeboetoe y otros v. Surinam 1993; Bámaca v. Guatemala 2000; Barrios Altos v. Perú 2001; Cantoral v. Perú 2000; Candia 2015; Martínez C. 2018; Calderón, 2015; Chitay y otros v. Guatemala 2010; Godínez v. Honduras 1989; Trujillo v. Bolivia 2002; Goiburú y otros v. Paraguay 2006; Gomes y otros (Guerrilha do Araguaia) v. Brasil 2010; Ibsen y otro v. Bolivia 2010; La Cantuta v. Perú 2006; Ríos y otros v. Venezuela 2009; Masacre de las Dos Erres vs. Guatemala 2009; Penal Miguel Castro Castro v. Perú 2006; Perozo y otros v. Venezuela 2009; Sommer 2018; Velásquez v. Honduras 1988).

También se deben considerar las resoluciones de organismos internacionales adoptadas con relación a la temática para impulsar la adecuada implementación de las disposiciones de los Convenios de Ginebra; por ejemplo, la Resolución 60/147, aprobada por la Asamblea General el 16 de diciembre de 2005 sobre "Principios y directrices básicos sobre el derecho de las víctimas de violaciones manifiestas de las normas internacionales de derechos humanos y de violaciones graves del derecho internacional humanitario a interponer recursos y obtener reparaciones", que enfatiza que los Estados tienen la obligación de resarcir de manera adecuada a las víctimas de crímenes de guerra (V. Principios I.2.c., II.3.d., VI.10, 
VII.11.b y c, VIII.13, y en especial IX. Reparación de los daños sufridos), y representa una oportunidad para aumentar la presión internacional en la búsqueda incesante de las víctimas por una reparación integral, plena y satisfactoria, tanto en sus factores materiales como simbólicos, y representa un esfuerzo moral y político de la comunidad internacional para ampliar el marco de principios y criterios encaminados a otorgarle mayor legitimidad y dirección a políticas domésticas y cooperantes de tratamiento al daño producido por injusticias y abusos pasados violentos (Vera 2008; Zegveld 2003).

Por otra parte, la obligación de indemnizar los daños causados por violaciones del DIH es recordada en varias resoluciones aprobadas por el Consejo de Seguridad (por ejemplo, Res. 387, 455, 471, 527, 571, 687, $692,827)$ y la Asamblea General de las Naciones Unidas (por ejemplo, Res. 50/22, 51/233 y 56/83). Y en otras resoluciones de organizaciones internacionales; por ejemplo, Comisión de Derechos Humanos de las Naciones Unidas, Res. 1995/77, pár. 253; Subcomisión de Derechos Humanos de las Naciones Unidas, Res. 1993/23, pár. 254 y Res. 1995/5, pár. 255; Secretario General de las Naciones Unidas, Informe sobre las causas de los conflictos y el fomento de la paz duradera y el desarrollo sostenible en África, pár. 258; Naciones Unidas, Comisión de la Verdad para El Salvador, Informe, pár. 262 (Henckaerts y Doswald-Beck 2007).

Lo propio ocurre respecto de documentos atinentes emanados del comité de redacción de los Convenios, en este caso, la Conferencia Internacional de la Cruz Roja, que en 2011 estableció un plan de acción cuatrienal para la aplicación del derecho internacional humanitario (Comité Internacional de la Cruz Roja 2011), cuyo objetivo 4, relativo a "mejorar la incorporación y la represión de las violaciones graves del derecho internacional humanitario", indica al respecto que los Estados han reconocido la importancia de adoptar soluciones complementarias a las sanciones penales y de establecer mecanismos para la aplicación efectiva de las sanciones disciplinarias, financieras o de otra índole por violaciones del derecho internacional humanitario.

Con todo, la obligación de reparación de las víctimas producto de violaciones al DIH tiene su fuente en el derecho internacional consuetudinario. En efecto, el Comité Internacional de la Cruz Roja realizó un estudio con base en la práctica de más de 150 Estados, y elaboró una lista de las normas consuetudinarias del DIH, en la que se incluye "el Esta- 
do responsable de violaciones del derecho internacional humanitario está obligado a reparar íntegramente la pérdida o la lesión causada" (Comité Internacional de la Cruz Roja 2009).

\section{CONCLUSIONES}

1. La jurisprudencia chilena muestra una falta de uniformidad respecto de la interpretación y aplicación de los Convenios de Ginebra de 1949, principal fuente escrita del DIH en materia de solicitudes de indemnización de perjuicios derivados de crímenes internacionales que violaron las normas humanitarias durante los estados de sitios por conmoción interior declarados en Chile en 1973.

2. La postura en contra de la procedencia de la imprescriptibilidad de las acciones civiles reparatorias de graves violaciones al DIH sostiene que razones de paz social y de certeza jurídica posibilitan la aplicación de la prescripción de las acciones civiles emanadas del ilícito, pues se considera que la imprescriptibilidad de la acción penal no arrastra la de las acciones civiles. Para considerarlas imprescriptibles, a su juicio, se requeriría la existencia de una norma expresa que declarara la improcedencia de la prescripción, que no consta en el derecho internacional. Además, por un lado, se considera que el Estado chileno ya ha dado cumplimiento al resarcimiento a través de beneficios otorgados por las leyes 19.123 y 19.980, y, por otro, que los tribunales penales son incompetentes para conocer de las indemnizaciones de perjuicios solicitadas, pues en sede penal no se puede demandar civilmente al tercero responsable (en este caso, el Estado chileno).

3. La tendencia jurisprudencial en la Corte Suprema chilena, predominante desde 2015, sostiene que la reparación en caso de responsabilidad internacional del Estado derivada de la comisión de ilícitos que vulneran las normas del DIH garantiza la paz social, y que la imprescriptibilidad de las acciones para perseguir tal responsabilidad rige tanto para el ámbito civil como para el penal, pues las normas internacionales humanitarias reconocen, respetan y promueven la dignidad del hombre, debiéndose compensar adecuadamente a las víctimas y sobrevivientes de violaciones graves a esa dignidad. Por tanto, se afirma la existencia de un verdadero estatuto internacional de imprescriptibilidad integral, cuya fuente es de origen consuetudinario, y que representan principios básicos del derecho internacio-

Esta obra está bajo una Licencia Creative Commons

Atribución-NoComercial-SinDerivar 4.0 Internacional, IIJ-UNAM.

Boletín Mexicano de Derecho Comparado, núm. 156, pp. 1361-1382. 
nal de carácter de ius cogens. Además, aluden al desarrollo de la materia en el seno de la Corte Interamericana de Derechos Humanos.

4. Esta última jurisprudencia sería más acorde a una interpretación de los Convenios de Ginebra conforme a las pautas de interpretación aplicables a las normas internacionales, pues si se examina el estatuto de responsabilidad recogido en los Convenios de Ginebra para el caso de violaciones graves del DIH, los trabajos preparatorios de su codificación, los acuerdos concertados después del término de conflictos armados para reparar a las víctimas de infracciones al $\mathrm{DIH}$, las resoluciones atinentes al tópico en estudio adoptadas por organismos internacionales, los documentos emanados de la Conferencia Internacional de la Cruz Roja, y las normas consuetudinarias en materia de reparación civil por infracciones al derecho internacional, se concluye que la reparación pecuniaria de las víctimas (o sus familiares) de violaciones a la dignidad humana es un principio básico del DIH.

\section{REFERENCIAS BIBLIOGRÁFICAS}

Acosta Estévez, José B., "Normas de ius cogens, efecto erga omnes, crimen internacional y la teoría de los círculos concéntricos", Anuario de Derecho Internacional, 1995.

Aguilar Cavallo, Gonzalo, "La reparación civil en casos de violaciones a los derechos humanos y la imprescriptibilidad de la acción civil: estudio de casos", Revista Derecho del Estado 22, 2009.

Bustos Valderrama, Crisólogo, "Los crímenes de derecho internacional y los conflictos armados no internacionales", Revista de Derecho Consejo de Defensa del Estado 2, 2000.

CALDERÓn, Jorge, La evolución de la "reparación integral" en la jurisprudencia de la Corte Interamericana de Derechos Humanos, México, Comisión Nacional de los Derechos Humanos, 2015.

Candia, Gonzalo, "Restitutio in integrum", Eunomía. Revista en Cultura de la Legalidad 9, 2015-2016.

Cebada Romero, Alicia, "Los conceptos de obligación erga omnes, ius cogens y violación grave a la luz del nuevo proyecto de la CDI sobre responsabilidad de los Estados por hechos ilícitos", Revista Electrónica de Estudios Internacionales, 2002. 
Comisión de Derecho InTERnacional, Artículos sobre responsabilidad del Estado por hechos internacionalmente ilícitos, A/56/10, 2001.

COMITÉ INTERNACIONAL DE LA GRUZ RoJA, Estudio de derecho internacional humanitario consuetudinario, Bogotá, CICR, 2009.

Comité Internacional DE LA CRUZ RoJA, XXXI Conferencia Internacional de la Cruz Roja y la Media Luna Roja, Ginebra: 31IC/11/5.1.3DR, 2011.

Comité InTERnacional De la CRUz Roja, Estado de ratificación de los principales tratados de DIH, 2014, disponible en: http://wrwr.icrc.org/spa/ resources/documents/misc/party_main_treaties.htm.

Comité Internacional De LA Gruz Roja. Convention (I) for the Amelioration of the Condition of the Wounded and Sick in Armed Forces in the Field. Geneva. Commentary of 2016, Article 51: Responsabilities of the contracting parties, disponible en: https://ihl-databases.icrc.org/applic/ihl/ihl.nsf/vw Trea ties 1949.xsp.

Comité Internacional de la Gruz Roja, Protocol Additional to the Geneva Conventions of 12 August 1949, and relating to the Protection of Victims of International Armed Conflicts (Protocol I), 8 June 1977. Commentary of 1987: Responsibility, disponible en: https://ihl-databases.icrc.org/applic/ihl/ihl.nsf/ vw Treaties 1949.xsp.

Comité Internacional De la Cruz Roja, Los Convenios de Ginebra de 1949 y sus Protocolos adicionales, 2014, disponible en: https://wrwe.icrc. org/es/document/los-convenios-de-ginebra-de-1949-y-sus-protocolos-adicio nales?.gclid $=C$ ijwKCAjwibzsBRAMEiwA 1pHZrmbwWCQ-ozUWJ6BdU dBUX_W9vwDPueVRoyG1XVIAURut7PfuvfwC5hoCY6cQAvD_BwE.

CRAWFORD, James, Los artículos de la Comisión de Derecho internacional sobre la Responsabilidad Internacional del Estado, Cambrige, Dykinson, 2004.

FEDDERSEN, Mayra, La prescripción de las acciones reparatorias en la jurisprudencia de la Corte Suprema. Santiago: Centro de Derechos Humanos, Universidad Diego Portales, 2011.

GALDÁMEZ ZELADA, Liliana, Impunidad y tutela judicial de graves violaciones a los Derechos Humanos, Santiago, Librotecnia, 2011.

Gómez-Robledo Verduzco, Alonso, "Aspectos de la reparación en derecho internacional", en Temas selectos de derecho internacional, México, UNAM, 2003.

Gutiérrez EsPadA, Cesáreo, y Cervell Hortal, María José, El derecho internacional en la encrucijada, Madrid, Trotta, 2008.

Esta obra está bajo una Licencia Creative Commons

Atribución-NoComercial-SinDerivar 4.0 Internacional, IIJ-UNAM.

Boletín Mexicano de Derecho Comparado, núm. 156, pp. 1361-1382. 
GREIFF, Pablo de, "Justicia y reparaciones", en Fusticia transicional. Manual para América Latina, ed. Félix Reátegui, Brasilia y Nueva York, Comisión de Amnistía del Ministerio de Justicia de Brasil, 2011.

HenckAerts, Jean-Marie y DoswALD-BECK, Louise, El derecho internacional humanitario consuetudinario, Buenos Aires, Comité Internacional de la Cruz Roja, 2007.

Horvitz Lennon, María Inés, "Amnistía y prescripción en causas sobre violación de derechos humanos en Chile", Anuario de Derechos Humanos, 2006.

Jiménez de Aréchaga, Eduardo et al., Derecho internacional público. Principios, normas y estructuras, vol. 1, Montevideo, Fundación de Cultura Universitaria, 2005.

MARTínez, D., "La imprescriptibilidad de las acciones civiles por daños y perjuicios emanadas de delitos de lesa humanidad", Derechos en Acción 4, 2017, disponible en: https://revistas.unlp.edu.ar/ReDeA/article/view/3914.

MARTínez, Claudia M., "La reparación integral a las víctimas del conflicto armado en Colombia en el marco de la justicia transicional", PH.D. thesis, Madrid, Universidad Complutense de Madrid, 2018.

Meron, Theodor, "The Geneva Conventions as Customary Law", American Fournal of International Law 81, 1987.

NAGIONES Unidas, "Conclusions of the work of the Study Group on the Fragmentation of International Law: Difficulties arising from the Diversification and Expansion of International Law", 2002, disponible en: https://wrerr.legal-tools.org/doc/146c60/pdf.

Novak Talavera, Fabián, "Los criterios para la interpretación de los tratados", Themis, Revista de Derecho 63, 2013.

Pagliari, Arturo Santiago, Curso de derecho internacional público. Córdoba, Advocatus, 2007.

SÁnchez PATRÓn, José Manuel, "El derecho internacional ante los crímenes cometidos contra la población civil", Anuario Español de Derecho Internacional 30, 2014.

Sandoz, Yves, El Comité Internacional de la Cruz Roja: guardián del derecho Internacional humanitario, 1998, disponible en: https://wwwe.icrc.org/es/doc/ resources/documents/misc/about-the-icrc-311298.htm.

SOMMER, Christian, "La imprescriptibilidad de la acción reparatoria por crímenes de lesa humanidad y la responsabilidad del Estado. Comen- 
tarios sobre la jurisprudencia y la legislación argentinas", Revista Derecho del Estado 41, 2018.

SHAw, Malcolm, International Law. Cambridge, Cambridge University Press, 2008.

Vera Piñeros, Diego, "Desarrollo internacional de un concepto de reparación a las víctimas de derechos humanos e infracciones al derecho internacional humanitario: complementos a la perspectiva de la ONU", Pap. Polit, Bogotá, 13 (2), 2008.

ZEGVELD, Liesbeth, "Remedies for Victims of Violations of International Humanitarian Law", International Review of the Red Cross 851, 2003.

ZEGVeLD, Liesbeth, "Victims' Reparations Claims and International Criminal Courts: Incompatible Values?”, fournal of International Criminal Fustice 8, 2010. 